\title{
Green, Cost-Effective Simultaneous Assay of Chloramphenicol, Methylparaben, and Propylparaben in Eye-Drops by Capillary Zone Electrophoresis
}

\author{
Thi Thanh Vuong Tong $\mathbb{D}^{1},{ }^{1}$ Thi Thoa Cao ${ }^{D},{ }^{1}$ Nguyen Ha Tran $\mathbb{D}^{1},{ }^{1}$ Thi Kim Van Le $\mathbb{D}^{2}$, \\ and Dinh Chi Le $\left.{ }^{3}\right)^{3}$ \\ ${ }^{1}$ Department of Analytical Chemistry and Toxicology, Hanoi University of Pharmacy, Hanoi, Vietnam \\ ${ }^{2}$ National Institute of Medicinal Materials, Hanoi, Vietnam \\ ${ }^{3}$ National Institute of Pharmaceutical Technology, Hanoi University of Pharmacy, Hanoi, Vietnam
}

Correspondence should be addressed to Dinh Chi Le; ledinhchi@gmail.com

Received 8 February 2021; Revised 16 March 2021; Accepted 26 March 2021; Published 12 April 2021

Academic Editor: Tien Duc Pham

Copyright (C) 2021 Thi Thanh Vuong Tong et al. This is an open access article distributed under the Creative Commons Attribution License, which permits unrestricted use, distribution, and reproduction in any medium, provided the original work is properly cited.

\begin{abstract}
A green, cost-effective, and simple capillary zone electrophoresis (CZE) method was developed and validated for simultaneous determination of chloramphenicol, methylparaben, and propylparaben in eye-drops. With sodium tetraborate as background electrolyte (BGE), the apparent mobilities of chloramphenicol, methylparaben, and propylparaben increased and analysis time reduced when $\mathrm{pH}$ of $\mathrm{BGE}$ increased from 8.5 to 10.0 and concentration of BGE decreased from $40 \mathrm{mM}$ to $15 \mathrm{mM}$, but complete separation of chloramphenicol from other matrix components was achieved only with sodium tetraborate concentration at $30 \mathrm{mM}$ or higher and at $\mathrm{pH}=9.3$ or lower. The most suitable electrophoretic conditions for the intended application were a $30 \mathrm{mM}$ sodium tetraborate solution, $\mathrm{pH} 9.3$ as BGE, working voltage set at $25 \mathrm{kV}$, and UV detection at $280 \mathrm{~nm}$ at the cathodic extremity of the capillary. The final method was validated and proved to be reliable for assay of chloramphenicol, methylparaben, and propylparaben in eye-drops.
\end{abstract}

\section{Introduction}

Chloramphenicol is a broad-spectrum antibiotic effective against both Gram-positive and Gram-negative bacteria [1]. Due to its potential grave side effect (bone marrow aplasia) $[1,2]$, chloramphenicol is used mainly for local treatment of eye infections in form of eye-drops or ointments. Parabens are esters of p-hydroxybenzoic acid commonly used as antimicrobial preservatives thanks to their antibacterial activities [3]. However, in pharmaceutical preparations, only methylparaben and propylparaben are currently used as preservatives due to concerns regarding their safety [4]. So far, UV-Vis spectroscopy has been used for assay of chloramphenicol in pharmaceutical-grade raw material [5]; the high-performance liquid chromatography (HPLC) method using C18 column has been developed for the assay of chloramphenicol in pharmaceutical dosage forms [5] and biological sample [6]; and capillary zone electrophoresis (CZE) with amperometric detection has been used for quantifying chloramphenicol in blood [7] and eye-drops [8]. More recently, chloramphenicol in eye-drops was determined by the electrochemical method using a glassy carbon electrode modified by $\mathrm{Ho}^{3+} / \mathrm{Co}_{3} \mathrm{O}_{4}$ nanoflowers [9]. Propylparaben and methylparaben have been analyzed simultaneously in cosmetic products with reversed-phase HPLC [10], in pharmaceutical and cosmetic products with capillary electrophoresis with conventional UV detection [11], and in pharmaceutical preparations by microchip electrophoresis with conductivity detection [12]. Chloramphenicol and methylparaben were determined by UV spectrometry with 
multivariate calibration [13]. So far, HPLC is the most common technical choice for assay of chloramphenicol, propylparaben, and methylparaben, though no method for simultaneous analysis of these substances has been published up to now within the limit of our bibliography research. Despite many advantages provided by HPLC, the operational cost of this technique is quite high, particularly in large-scale analysis, such as in routine quality control or postmarketing surveillance of pharmaceutical products, for consuming high-quality solvents and chemicals and the cost for analytical columns. Most of the HPLC methods use organic solvents in mobile phases, which end up as organic waste, which is often a pollutant for the environment and hazardous for human health. In comparison to HPLC, CZE uses mostly aqueous electrolyte solutions in small quantities and low-cost fused-silica capillaries, which are much cheaper than high-quality organic solvents and chromatography columns, leading to much lower operational cost, material consumption, and, last but not less, no hazardous waste after analysis. Therefore, this technique is very costeffective and friendly with the environment, suitable for routine analysis of relatively simple samples containing ionized or ionizable analytes. Employing more extensively CZE-based methods can help quality control laboratories with limited resources in developing countries like Vietnam work more effectively in reserving the more robust and capable HPLC techniques for the most challenging analytical problems. In this study, a simple, cost-effective, and green capillary zone electrophoresis (CZE) method was developed for simultaneous assay of chloramphenicol, methylparaben, and propylparaben in eye-drops. The method was fully validated according to the current demands of ICH [14] and AOAC International [15], aiming at providing a reliable tool for use in routine quality control of eye-drops containing these analytes.

\section{Materials and Methods}

2.1. Instrumentation. 3D-CE capillary electrophoresis system of Agilent Technologies (Santa Clara, CA, USA) was used for method development and validation. This system was equipped with a PDA detector. The capillary zone electrophoresis separation was executed on a fused-silica capillary (total length: $35 \mathrm{~cm}$, effective length: $30 \mathrm{~cm}$, and inner diameter: $50 \mu \mathrm{m})$. Software ChemStation version B.03.01 of Agilent Technologies (Santa Clara, CA, USA) was used for data processing.

To measure and adjust the $\mathrm{pH}$ of sodium tetraborate solution, a pH meter CyberScan pH 510 of Eutech Instruments was used (Eutech Instruments Pte. Ltd., Singapore).

2.2. Chemicals and Reagents. Reference standards of chloramphenicol (purity 99.6\%), methylparaben (purity $100.0 \%$ ), and propylparaben (purity 99.9\%) were purchased from the National Institute of Drug Quality Control (Hanoi, Vietnam). Chloramphenicol eye-drops (containing nominally $32 \mathrm{mg}$ of chloramphenicol, $88 \mathrm{mg}$ of boric acid, $16 \mathrm{mg}$ of sodium borate, $16 \mathrm{mg}$ of sodium chloride, $1.44 \mathrm{mg}$ of methylparaben, and $0.16 \mathrm{mg}$ of propylparaben per vial of $8 \mathrm{ml}$ ) was purchased from the market. Sodium tetraborate, sodium hydroxide, and hydrochloric acid PA grade were purchased from Merck Vietnam (Ho Chi Minh City, Vietnam). All solutions were prepared by using deionized water. In case of sodium tetraborate solution, the $\mathrm{pH}$ was adjusted, whenever necessary, with $0.1 \mathrm{M}$ hydrochloric acid solution or $0.1 \mathrm{M}$ sodium hydroxide solution.

2.3. Electrophoretic Conditions. The background electrolyte was a $30 \mathrm{mM}$ solution of sodium tetraborate, $\mathrm{pH}$ 9.3. The analysis was carried out on an Agilent 3D-CE capillary electrophoresis apparatus equipped with a PDA detector set at $280 \mathrm{~nm}$ for recording electropherograms. The electrophoretic separation was conducted on a fused-silica capillary (total length: $35 \mathrm{~cm}$, effective length: $30 \mathrm{~cm}$, and inner diameter: $50 \mu \mathrm{m}$ ) maintained at $25^{\circ} \mathrm{C}$ with a voltage of $25 \mathrm{kV}$ applied on the two extremities of the capillary. The detection was done at the cathodic extremity of the capillary. The injection was done hydrodynamically on the anodic extremity of the capillary by applying a pressure of $50 \mathrm{mbar}$ in 15 seconds. Before each analysis, the capillary was prewashed consecutively in 2 minutes with deionized water, 1 minute with $0.1 \mathrm{M}$ solution of sodium hydroxide, 2 minutes with deionized water, and 2 minutes with background electrolyte. Detailed information about the selection of electrophoretic and prewash conditions was provided in section 3.1.

2.4. Preparation of Standard Solution. Stock standard solutions of chloramphenicol (about $4000 \mu \mathrm{g} / \mathrm{ml}$ ), methylparaben (about $1000 \mu \mathrm{g} / \mathrm{ml}$ ), and propylparaben (about $1000 \mu \mathrm{g} / \mathrm{ml}$ ) were prepared by dissolving an accurately weighed quantity of corresponding reference standard in deionized water. Mix standard solutions for routine analysis and method validation were prepared by accurate dilution of stock standard solutions to the intended concentration with deionized water. Working concentrations in mix standard solution for routine analysis were about $2000 \mu \mathrm{g} / \mathrm{ml}$ for chloramphenicol, $90 \mu \mathrm{g} / \mathrm{ml}$ for methylparaben, and $10 \mu \mathrm{g} / \mathrm{ml}$ for propylparaben. For method validation, 5 mix standard solutions having concentrations of each analyte at about $60.0 \%, 80.0 \%, 100.0 \%, 120.0 \%$, and $140.0 \%$ of respective working concentration were prepared for linearity study. Standard solutions were filtered through $0.2 \mu \mathrm{m}$ membrane filter before used for electrophoretic analysis.

2.5. Preparation of Sample Solution. To prepare the sample solution for routine analysis, one volume of eye-drops was diluted with one volume of deionized water. For method specificity evaluation, a solution in deionized water containing $88 \mathrm{mg}$ of boric acid, $16 \mathrm{mg}$ of sodium borate, and $16 \mathrm{mg}$ of sodium chloride per $8 \mathrm{ml}$ was used as a placebo. For the recovery study, different portions of placebo were spiked with chloramphenicol, methylparaben, and propylparaben at $80.0 \%, 100.0 \%$, and $120.0 \%$ of working concentration for each analyte (see 2.4 ). Three spiked solutions were prepared 
independently for each spiked level. Sample solutions were filtered through a $0.2 \mu \mathrm{m}$ membrane filter before used for electrophoretic analysis.

\subsection{Method Validation}

2.6.1. Specificity. The reliability of an analytical method depends firstly on its specificity, that is, the ability to distinguish between the analyte(s) and the other components in the sample matrix [16]. In this CZE method, it is assured by complete separation of peaks corresponding to chloramphenicol, methylparaben, and propylparaben from each other and from other possible peaks originating from the sample matrix. Specificity evaluation was done by injecting solutions of standard, sample, and placebo into the electrophoretic system.

2.6.2. Linearity. To evaluate the linearity of the method, mixed standard solutions prepared as described in 2.4 were injected into the capillary and analyzed. The linearity between concentration and peak area of each analyte was evaluated using the least square linear regression method, and the significance of linear regression was confirmed by a one-way ANOVA test if $P<0.05$.

2.6.3. Sensitivity. According to the current guideline Q2R1 of ICH [14], determining the limit of detection (LOD) and limit of quantification (LOQ) is not required for quantitative methods. However, it is necessary to assure that the LOQ of the method for each analyte was below the working concentration. Therefore, the limit of quantitation (LOQ) of each analyte was determined by analyzing solutions having different concentrations of chloramphenicol, methylparaben, and propylparaben and measuring the signal-to-noise ratio for each analyte. The limit of quantitation (LOQ) is the concentration giving a signal-to-noise ratio of about 10:1 with RSD of less than $10 \%$ with triplicate analysis [17].

2.6.4. Accuracy. The accuracy of the method was evaluated by the recovery rate of chloramphenicol, methylparaben, and propylparaben from a placebo solution spiked with these analytes (as described in 2.5) [18].

2.6.5. Precision. The precision of the CZE method was validated in terms of system suitability, repeatability, and intermediate precision [14-16, 19].

The system suitability was determined by six measurements of a mixed standard solution containing each analyte at $100 \%$ of working concentration on the same day [15]. Repeatability and intermediate precision were determined by six measurements of a sample solution containing each analyte at approximately $100 \%$ of working concentration on the same day and on two different days, respectively.

2.6.6. Robustness. The robustness of the method was verified by assessing the variation of results after minor changes in the experimental conditions [20]. In this study, the following changes were made:

(i) Voltage: $\pm 2 \mathrm{kV}$.

(ii) Injection pressure: \pm 5 mbar.

At each condition, mixed standard solution of chloramphenicol, methylparaben, and propylparaben and sample solutions at $100 \%$ of working concentration were injected into capillary. The robustness of the method was evaluated from the RSD of peak area for each analyte after three consecutive injections of standard solution and the RSD of the content of chloramphenicol, methylparaben, and propylparaben from sample solutions.

\section{Results and Discussion}

\subsection{Method Development and Optimization}

3.1.1. Selection of Background Electrolyte. In this study, sodium tetraborate was used to prepare the background electrolyte solution. It has a value of $\mathrm{pKa}$ of about 9; therefore, it produces an electroosmotic flow (EOF) toward cathode in a fused-silica capillary due to the deprotonation of silanol group on the inner surface [21]. At $\mathrm{pH}$ from 6.5 upward, the parabens (Figures 1(b) and $1(\mathrm{c})$ ), began to deprotonate and became negatively charged, and $\mathrm{pKa}$ values of both methylparaben and propylparaben were about 8.47 [22]. Chloramphenicol, in contrast, was itself neutral in the $\mathrm{pH}$ range up to 11 [23], but tetraborate was known to form negatively charged complex with hydroxyl groups of polyol substances [24], including chloramphenicol (Figure 1(a)) [25] in aqueous solution. Therefore, in sodium tetraborate solution, chloramphenicol, methylparaben, and propylparaben were anions and migrated toward cathode with apparent mobility slower than that of EOF, and they can be simultaneously separated and detected at the cathode side of the capillary. To obtain suitable electrophoretic conditions for the final method, the concentration of sodium tetraborate was varied from $15 \mathrm{mM}$ to $40 \mathrm{mM}$ and the $\mathrm{pH}$ was varied from 8.5 to 10.0 . The measured $\mathrm{pH}$ of unadjusted sodium tetraborate solutions from $15 \mathrm{mM}$ to $40 \mathrm{mM}$ varied within the range of $9.3 \pm 0.1$, so the influence of $\mathrm{pH}$ was investigated at 8.5 (near the pKa of methylparaben and propylparaben), 9.3 (around original $\mathrm{pH}$ ), and 10.0 (higher than the original $\mathrm{pH}$ ). The working voltage was investigated from $5 \mathrm{kV}$ to $25 \mathrm{kV}$, taking into account the maximum acceptable current (not exceeding $100 \mu \mathrm{A}$ ) imposed by the manufacturer of the CE apparatus.

In terms of working voltage, a preliminary study on different concentrations and $\mathrm{pH}$ of sodium tetraborate solutions pointed out that, at a concentration of $40 \mathrm{mM}$, the working voltage cannot be set higher than $15 \mathrm{kV}$, whereas, at $15 \mathrm{mM}$ and $30 \mathrm{mM}$, the working voltage can go up to $25 \mathrm{kV}$, as shown in Figure 2. When the concentration of sodium tetraborate was fixed, $\mathrm{pH}$ variation from 8.5 to $10.0 \mathrm{did}$ not affect the range of applicable working voltage (see Figure 2). In consequence, with $40 \mathrm{mM}$ sodium tetraborate solution, lower maximum voltage led to longer analysis time (Figure 3(c)) comparing to analysis times obtained with $15 \mathrm{mM}$ (Figures 3(a) to 3(c)) and $30 \mathrm{mM}$ solutions (Figures 3(d) to 3(f)). 
<smiles>O=C(N[C@@H](CO)[C@H](O)c1ccc([N+](=O)[O-])cc1)C(Cl)Cl</smiles>

(a)<smiles>COC(=O)c1ccc(O)cc1</smiles>

(b)<smiles>CCCOC(=O)c1ccc(O)cc1</smiles>

(c)

FIGURE 1: Structural formulas of chloramphenicol (a), methylparaben (b), and propylparaben (c).

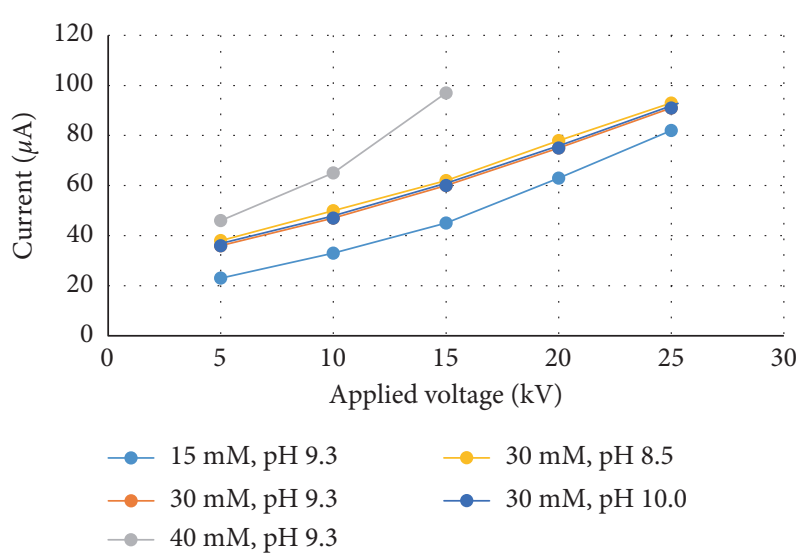

FIGURE 2: Relationship between the current and applied voltage at different concentrations and $\mathrm{pH}$ of sodium tetraborate solution.

In all investigated conditions of $\mathrm{BGE}$, the migration order among the analytes remained the same, chloramphenicol had the shortest migration time, followed by propylparaben, and methylparaben had the longest migration time (as shown in the electropherograms of Figure 3). The apparent mobilities of the three analytes increased when the $\mathrm{pH}$ increased from 8.5 to 10.0 at the same concentration of sodium tetraborate (Figure 4) due to the increase of EOF. Therefore, at the same concentration of sodium tetraborate, analysis time was the shortest at $\mathrm{pH}=10.0$ and the longest at $\mathrm{pH}=8.5$ (see Figures 3(a) to 3(c) at $15 \mathrm{mM}$ and Figures 3(d) to $3(\mathrm{f})$ at $30 \mathrm{mM}$ ). Similarly, apparent mobilities of all analytes increased when the concentration of sodium tetraborate reduced from $30 \mathrm{mM}$ (Figures $3(\mathrm{~d})$ to $3(\mathrm{f})$ ) to $15 \mathrm{mM}$ (Figures 3(a) to 3(c)) when working voltage was set at $25 \mathrm{kV}$.

The three analytes were well separated among them, but the resolution reduced drastically at $\mathrm{pH}$ 8.5. At this $\mathrm{pH}$, close to the $\mathrm{pKa}$ of methylparaben and propylparaben, perhaps because their ionization reduced, their apparent mobilities were closer to one another and closer to that of chloramphenicol than at $\mathrm{pH}=9.3$ or 10 (Figure 4 ), causing the loss in resolution.

While the separation of chloramphenicol from propylparaben and methylparaben was easily obtained, the separation between chloramphenicol and other matrix components of the eye-drops which migrated just before the peak of chloramphenicol was more difficult. The peak of chloramphenicol was completely separated with $30 \mathrm{mM}$ sodium tetraborate solution at $\mathrm{pH}=9.3$ or 8.5 (Figures 3(e) and 3(f)) and with $40 \mathrm{mM}$ sodium tetraborate solution (Figure $3(\mathrm{~g})$ ). In contrast, no complete separation was achieved with $15 \mathrm{mM}$ sodium tetraborate solution at $\mathrm{pH}$ from 8.5 to 10.0 (see Figures 3(a) to 3(c)). With $30 \mathrm{mM}$ sodium tetraborate at $\mathrm{pH} 10.0$ (Figure 3(d)), stronger EOF and higher apparent mobility of chloramphenicol led to shorter migration time but were insufficient in mobility difference with some matrix component(s), and the peak of chloramphenicol was not completely separated.

So, for these particular eye-drops, due to the electrophoretic characteristics of its components, the most suitable background electrolyte was $30 \mathrm{mM}$ sodium tetraborate solution, $\mathrm{pH}$ 9.3, because it provided complete separation of chloramphenicol, propylparaben, and methylparaben from each other and from other matrix components at the shortest time (less than 6 minutes, as shown in Figure 3(e)). This $\mathrm{pH}$ was also close to the original $\mathrm{pH}$ of $30 \mathrm{mM}$ sodium tetraborate solution; therefore, the $\mathrm{pH}$ adjustment of background electrolyte would be easier in routine application.

The experimental results also pointed out that quicker simultaneous assay of chloramphenicol, methylparaben, and propylparaben may be possible with $15 \mathrm{mM}$ sodium tetraborate solution at $\mathrm{pH}=10$ in about 2.6 minutes (Figure 3(a)) in case of a sample with less matrix interference or in combination with a more elaborate sample preparation procedure (like an extraction step to isolate analytes from sample matrix). But in the latter case, any gain in analysis time might be compromised by the need of more timeconsuming sample preparation.

3.1.2. Selection of Detection Wavelength. The UV-Vis spectra of chloramphenicol, methylparaben, and propylparaben measured at the detection window of the capillary are shown in Figure 5. Due to their structural similarity, both methylparaben (Figure 5(b)) and propylparaben (Figure 5(c)) had an absorption maximum at $280 \mathrm{~nm}$, whereas chloramphenicol (Figure 5(a)) had an absorption maximum at $272 \mathrm{~nm}$. Because, in the eye-drops, the concentration of chloramphenicol was much higher than those of methylparaben and propylparaben, the wavelength for recording electropherograms was selected at $280 \mathrm{~nm}$ to give priority to analytes with lower concentrations in sample. 


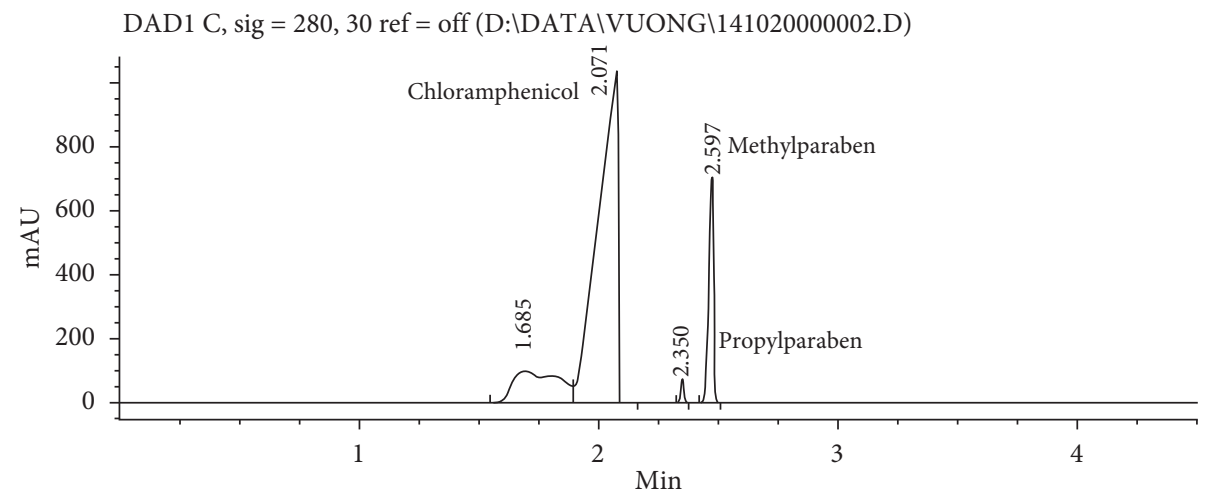

(a)

DAD1 C, sig = 280, 30 ref $=$ off $(D:|D A T A| V U O N G \backslash 141020000003 . D)$

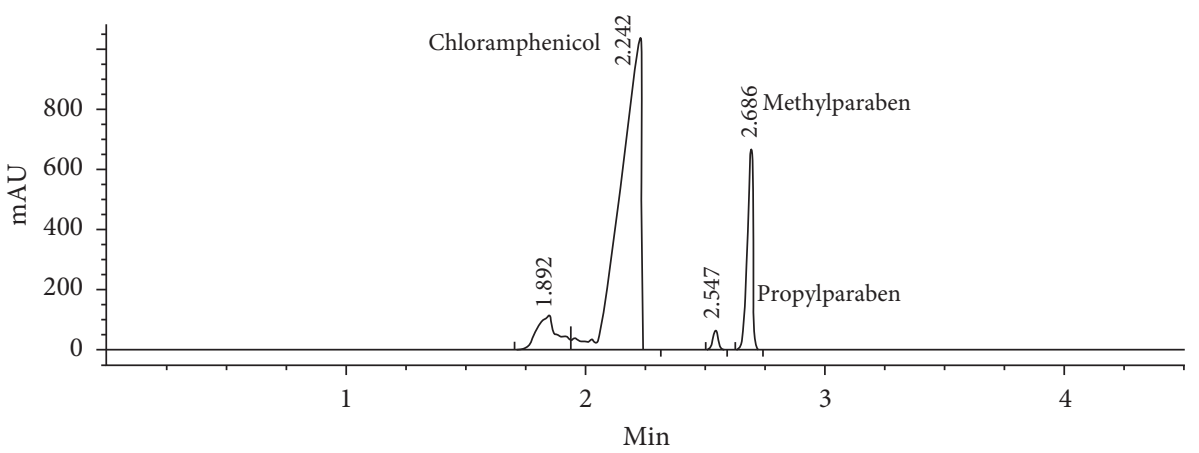

(b)

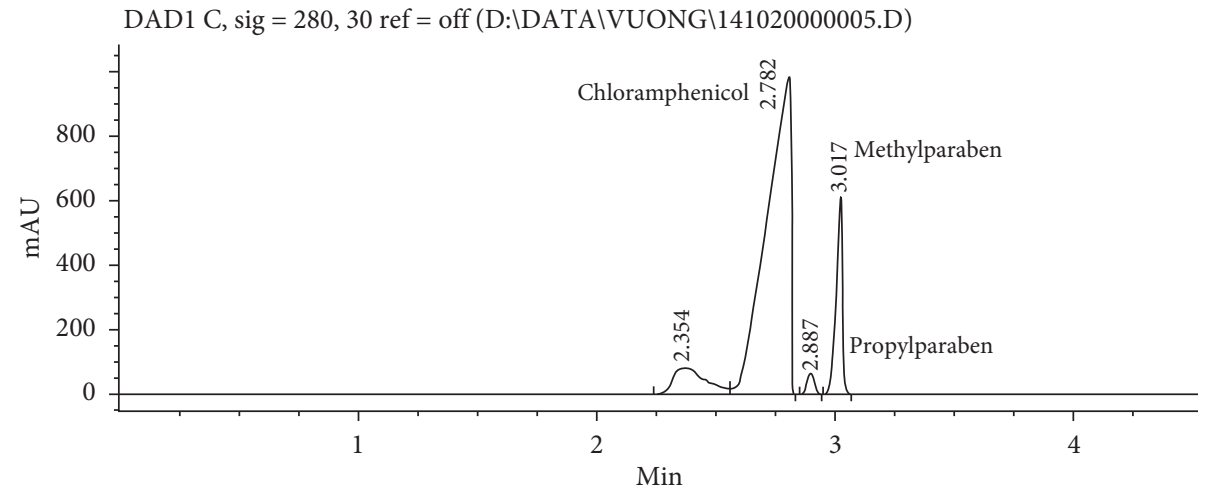

(c)

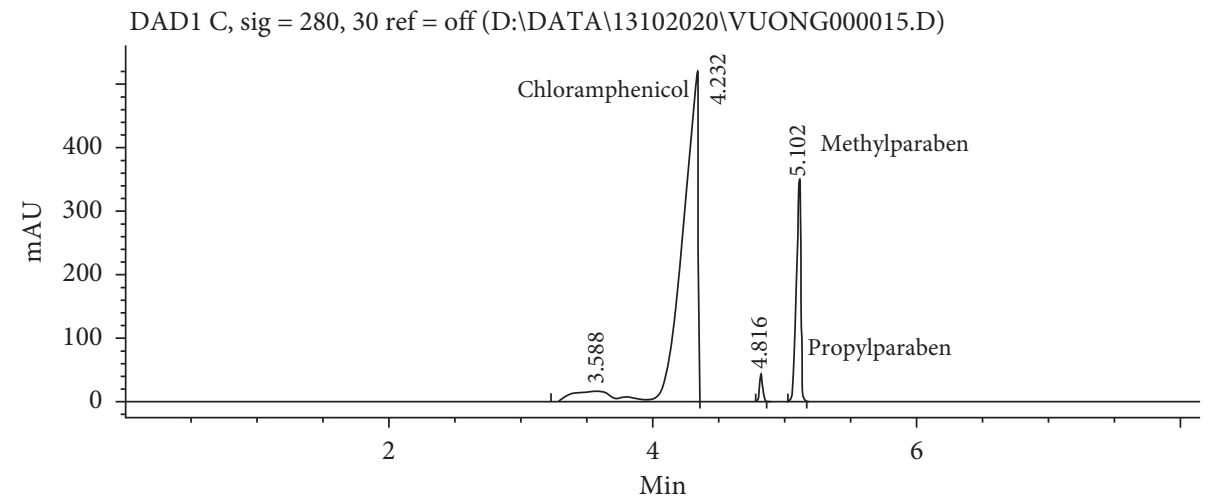

(d)

FIgURe 3: Continued. 


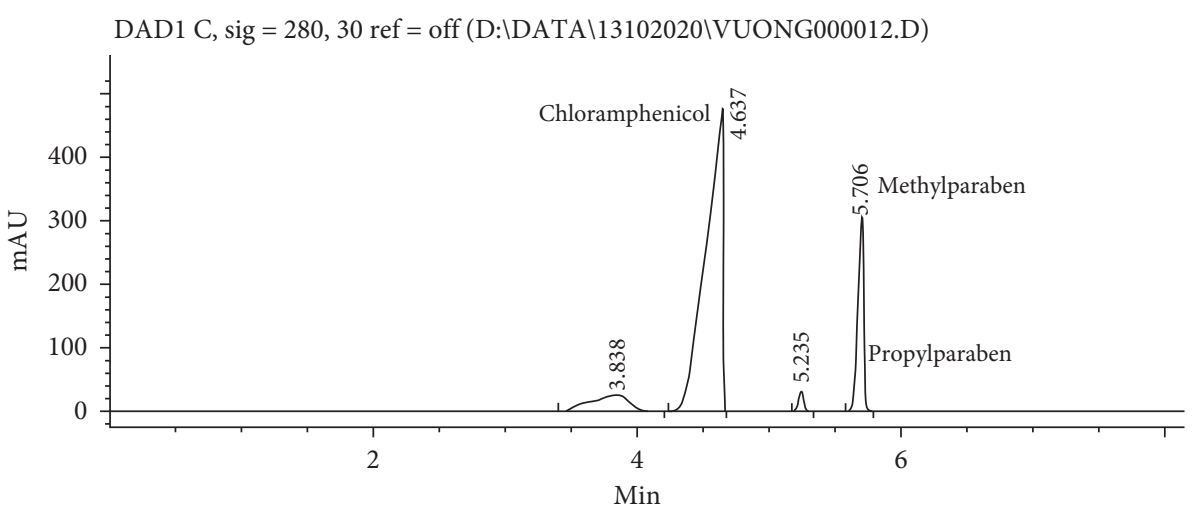

(e)

DAD1 C, sig = 280, 30 ref = off (D:|DATA \13102020\VUONG000014.D)

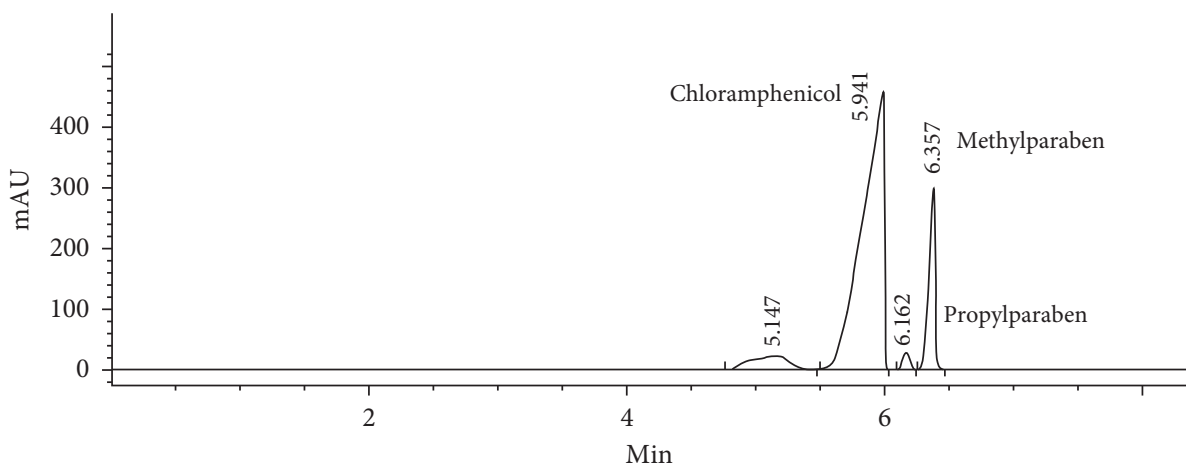

(f)

DAD1 C, sig = 280, 30 ref $=$ off (D:IDATA $08102020 \backslash$ VUONG000002.D)

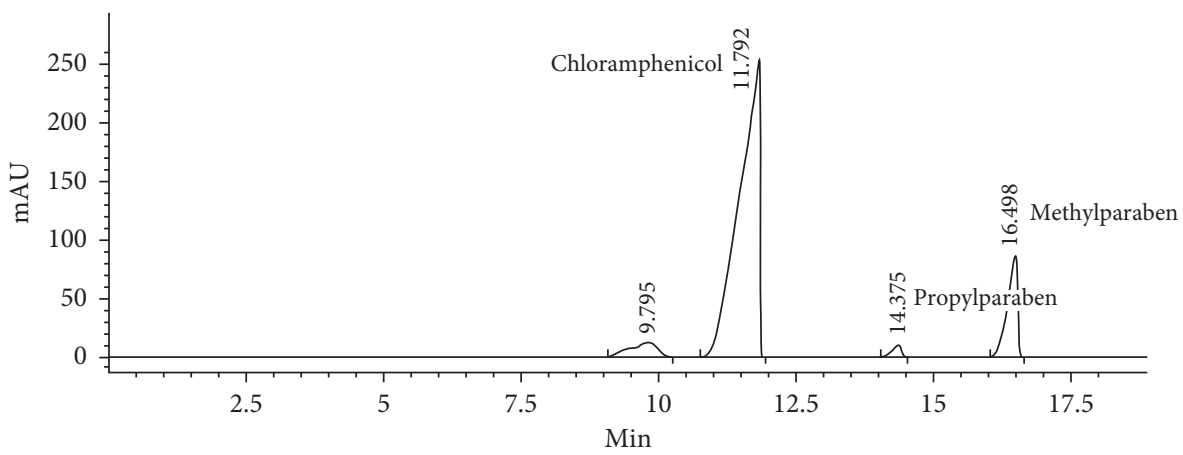

(g)

Figure 3: Electropherograms at different concentrations and $\mathrm{pHs}$ of sodium tetraborate solution (a): $15 \mathrm{mM}, \mathrm{pH}=10 ;(\mathrm{b}): 15 \mathrm{mM}$, $\mathrm{pH}=9.3$; (c): $15 \mathrm{mM}, \mathrm{pH}=8.5$; (d): $30 \mathrm{mM}, \mathrm{pH}=10$; (e): $30 \mathrm{mM}, \mathrm{pH}=9.3$; (f): $30 \mathrm{mM}, \mathrm{pH}=8.5$; and (g): $40 \mathrm{mM}, \mathrm{pH}=9.3$.

3.1.3. Selection of Prewash Program between Analyses. The key point for the success of a capillary electrophoresis method is maintaining the repeatability of migration time and peak response of analytes from one injection to another. The investigation of prewash conditions pointed out that only a 4-step prewash procedure using consecutively deionized water, sodium hydroxide $0.1 \mathrm{M}$, deionized water, and background electrolyte before each injection gave repeated migration time for all three analytes (with RSD $<2.0 \%$; see also information regarding system suitability in Table 1).
3.2. Method Validation. The final CZE method was fully validated according to the current requirements of $\mathrm{ICH}$ guideline Q2R1 [13] for the assay method. In terms of specificity, the validation was performed by comparing the electropherograms of placebo solution, standard solution, and sample solution after being injected separately into the CE system, and the results are shown in Figures 6(a)-6(c). In selected electrophoretic conditions, three analytes were completely separated, the peak of chloramphenicol was the first to arrive at the detection window, followed by that of propylparaben, and lastly, that of methylparaben 


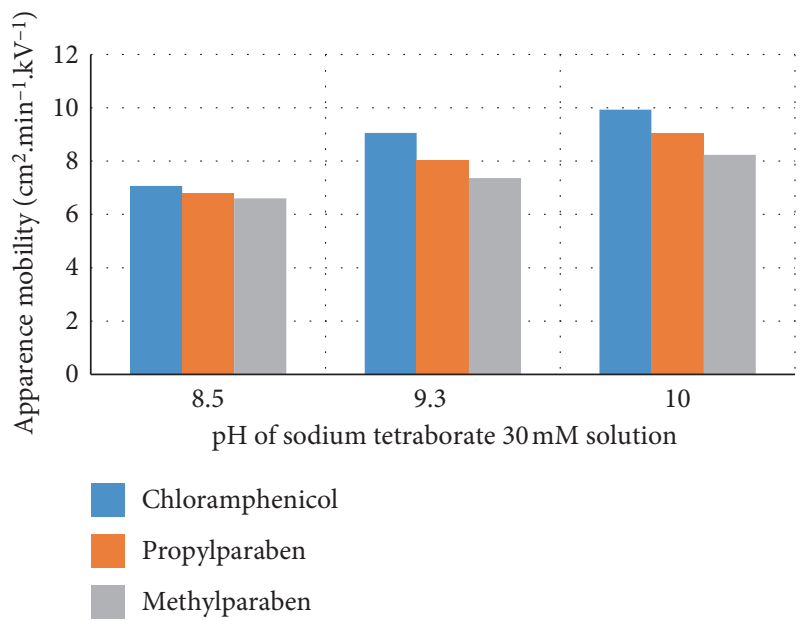

FIGURE 4: Relationship between the apparent mobility of analytes and $\mathrm{pH}$ of sodium tetraborate solution.

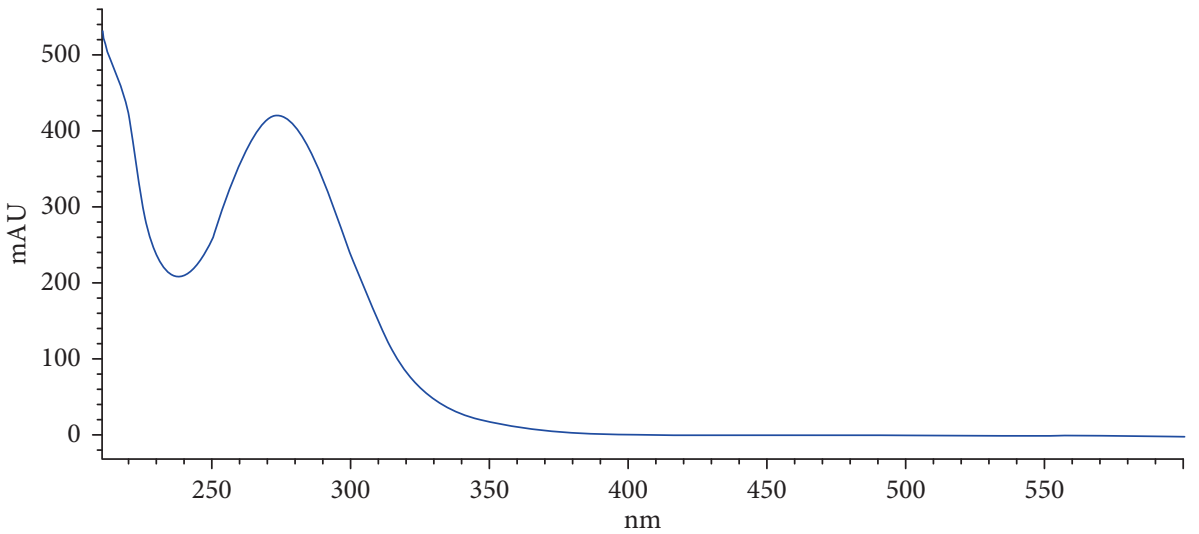

(a)

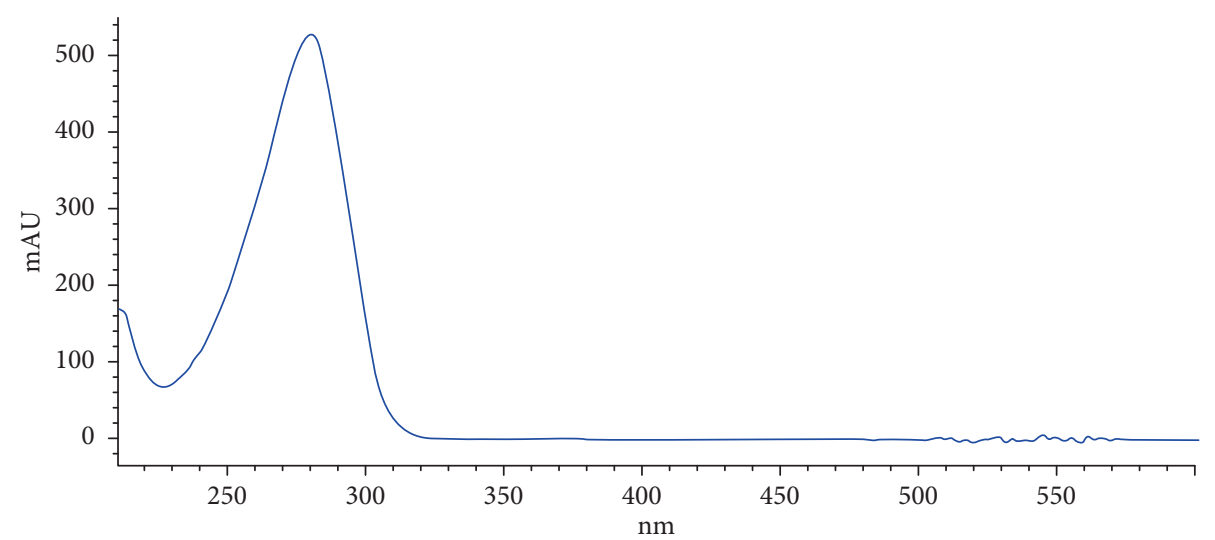

(b)

FIGURE 5: Continued. 


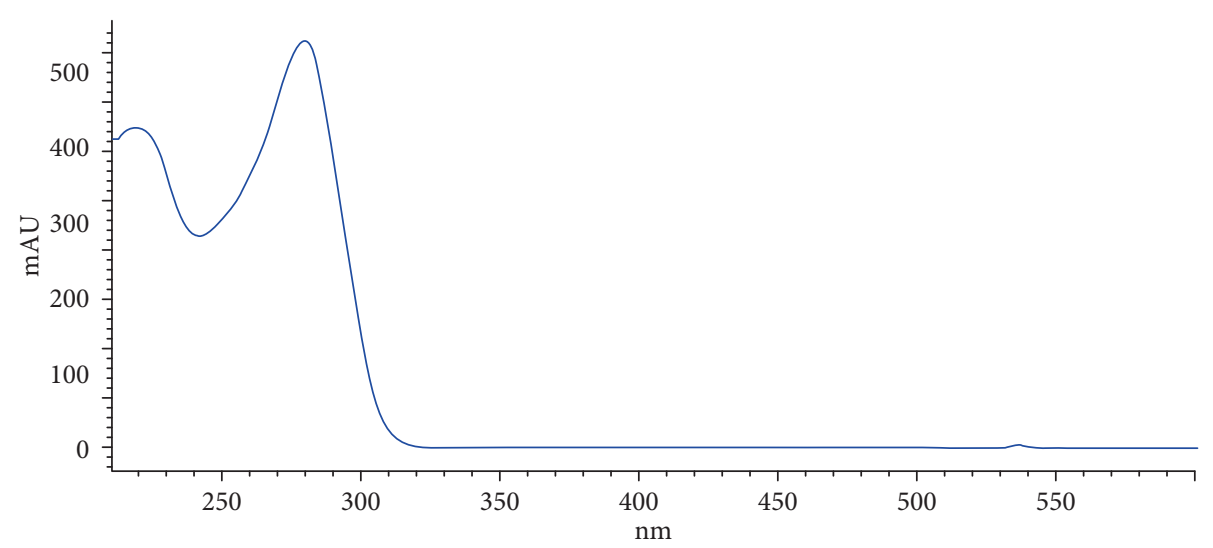

(c)

FIgURE 5: UV spectra of chloramphenicol (a), methylparaben (b), and propylparaben (c).

TABLe 1: Summary of validation results.

\begin{tabular}{|c|c|c|c|}
\hline Parameter & Chloramphenicol & Propylparaben & Methylparaben \\
\hline $\begin{array}{l}\text { System suitability } \\
\text { Migration time (RSD }(\%), n=6) \text {, } \\
\text { Peak area (RSD }(\%), n=6)\end{array}$ & $\begin{array}{l}1.1 \\
1.3\end{array}$ & $\begin{array}{l}1.1 \\
1.5\end{array}$ & $\begin{array}{l}1.2 \\
1.5\end{array}$ \\
\hline $\begin{array}{l}\text { Linearity } \\
\text { Concentration range }(\mu \mathrm{g} / \mathrm{ml}) \\
\text { Calibration curve } \\
R^{2}\end{array}$ & $\begin{array}{l}1202.7-2806.27 \\
y=2.3531 x+163.2 \\
0.9984\end{array}$ & $\begin{array}{l}\quad 6.7-15.7 \\
y=7.3451 x+1.27 \\
0.9991\end{array}$ & $\begin{aligned} & 55.5-129.5 \\
y= & 8.747 x+58.58 \\
& 0.9990\end{aligned}$ \\
\hline $\begin{array}{l}\text { Repeatability (RSD }(\%), n=6,1 \text { day) } \\
\text { Intermediate precision (RSD }(\%), n=12,2 \text { days) } \\
\text { Precision requirement, in RSD (\%), of AOAC International [14] } \\
\text { Accuracy ( } n=3 \text { at each level) } \\
\text { At } 80 \% \text { of working concentration } \\
\quad+\text { Recovery range }(\%) \\
\quad+\text { RSD }(\%)\end{array}$ & $\begin{array}{l}97.2-100.0 \\
1.5\end{array}$ & $\begin{array}{l}95.8-99.1 \\
1.7\end{array}$ & $\begin{array}{l}98.6-100.8 \\
1.1\end{array}$ \\
\hline $\begin{array}{l}\text { At } 100 \% \text { of working concentration } \\
+ \text { Recovery range }(\%) \\
\text { +RSD }(\%)\end{array}$ & $\begin{array}{l}98.7-100.1 \\
0.7\end{array}$ & $\begin{array}{c}100.6-104.3 \\
1.8\end{array}$ & $\begin{array}{l}94.8-96.7 \\
1.0\end{array}$ \\
\hline $\begin{array}{l}\text { At } 120 \% \text { of working concentration } \\
+ \text { Recovery range }(\%) \\
+ \text { RSD }(\%)\end{array}$ & $\begin{array}{l}99.1-101.5 \\
1.3\end{array}$ & $\begin{array}{l}97.2-100.5 \\
1.7\end{array}$ & $\begin{array}{c}95.5-97.5 \\
1.1\end{array}$ \\
\hline $\begin{array}{l}\text { Accuracy requirements, in recovery rate (\%), of AOAC International [14] } \\
\text { Limit of quantitation }(\mu \mathrm{g} / \mathrm{ml})\end{array}$ & $\begin{array}{c}95-105 \\
20.0\end{array}$ & $\begin{array}{l}80-110 \\
5.0\end{array}$ & $\begin{array}{l}90-107 \\
5.0\end{array}$ \\
\hline $\begin{array}{l}\text { Robustness } \\
\text { Variation of voltage ( } 3 \text { levels, } n=3 \text { for each level) } \\
\quad+\text { RSD (\%) of peak area } \\
\quad+\text { RSD }(\%) \text { of assay results }\end{array}$ & $\begin{array}{l}\leq 0.9 \\
\leq 0.8 \\
\end{array}$ & $\begin{array}{l}\leq 1.8 \\
\leq 1.8 \\
\end{array}$ & $\begin{array}{l}\leq 1.8 \\
\leq 1.6 \\
\end{array}$ \\
\hline $\begin{array}{l}\text { Variation of injection pressure ( } 3 \text { levels, } n=3 \text { for each level) } \\
\text { +RSD (\%) of peak area } \\
\text { +RSD (\%) of assay results }\end{array}$ & $\begin{array}{l}\leq 0.9 \\
\leq 0.9\end{array}$ & $\begin{array}{l}\leq 1.6 \\
\leq 1.8\end{array}$ & $\begin{array}{l}\leq 1.7 \\
\leq 1.5\end{array}$ \\
\hline One-way ANOVA for assay results using different experimental conditions & $P=0.948>0.05$ & $P=0.945>0.05$ & $P=0.907>0.05$ \\
\hline
\end{tabular}

(Figure 6(a)). In the electropherogram of a placebo, no peak appeared at migration times of chloramphenicol, propylparaben, and methylparaben (Figure 6(c)), whereas the electropherogram of eye-drops giving three peaks corresponding to those of chloramphenicol, propylparaben, and methylparaben was obtained with the standard solution in terms of migration times (Figure 6(b)). These results indicate that the electrophoretic conditions employed in this method were specified enough to separate the three analytes from one another as well as from other compositions of the eyedrops.

The quantitative validation results summarized in Table 1 also proved that the method met the current requirements of performance in terms of system suitability, 


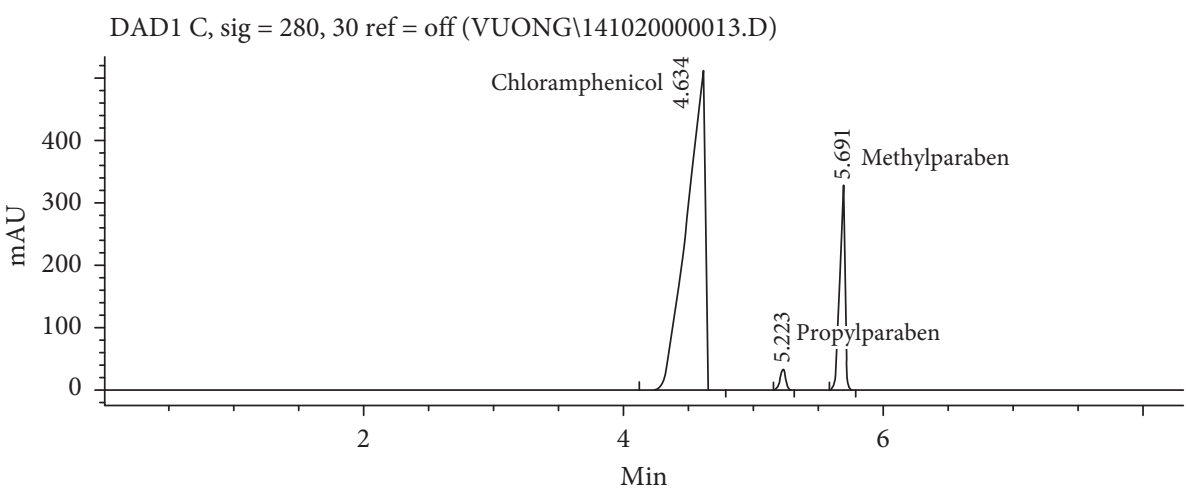

(a)

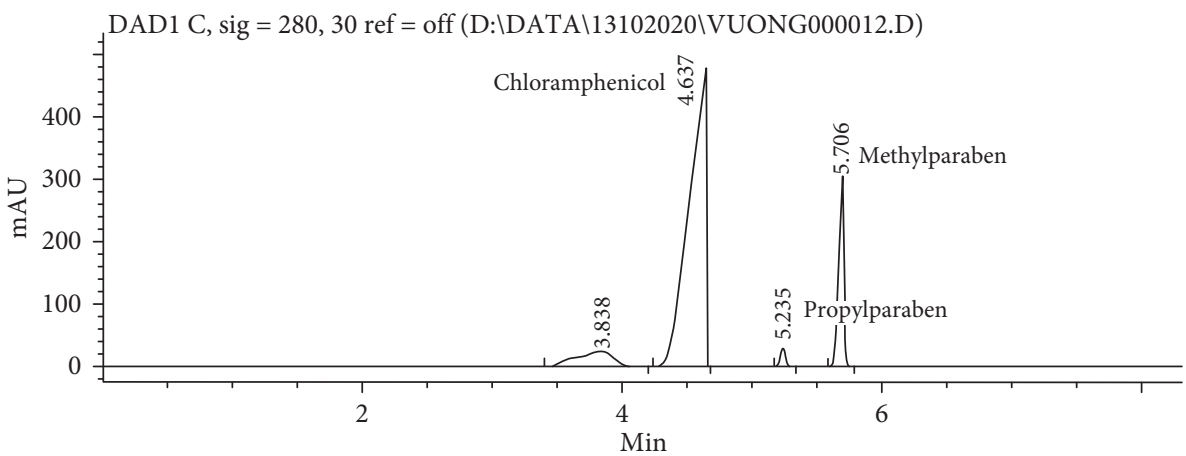

(b)

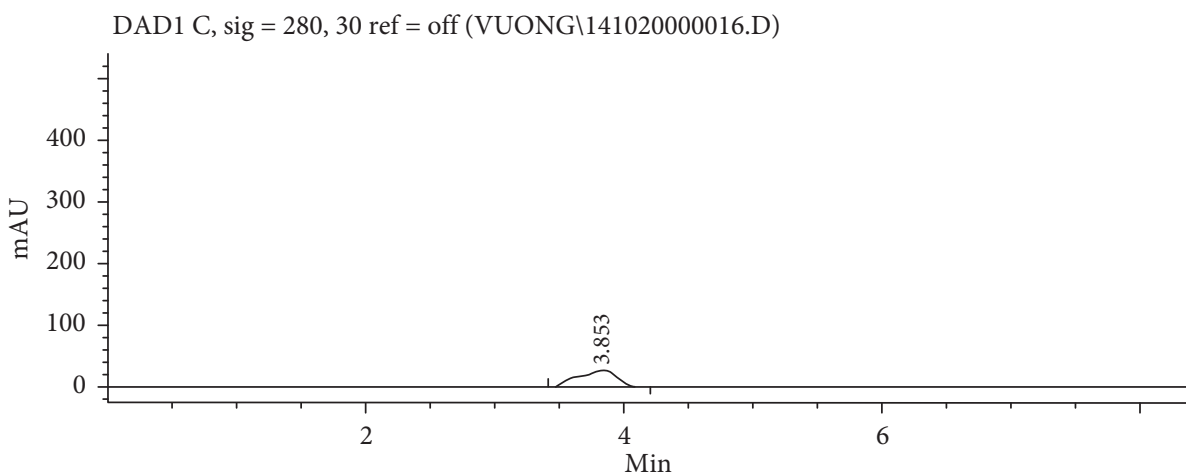

(c)

Figure 6: Typical electropherograms of mixed standard solution (a), eye-drops (b), and placebo (c).

linearity, precision (repeatability, intermediate precision), and accuracy when being applied for simultaneous assay of chloramphenicol, methylparaben, and propylparaben in eye-drops. The limits of quantitation for all three analytes were below their respective working concentrations, proving the adequate sensitivity of the method. And the method was also robust for minor changes in the experimental conditions because the robustness study showed no significant variation in electrophoretic response and assay results of all the three analytes (Table 1).

In comparison to other published methods, the CZE method developed by Uysal et al. [11] gave better LOQs for methylparaben (about $1 \mu \mathrm{g} / \mathrm{ml}$ ) and propylparaben (about $0.85 \mu \mathrm{g} / \mathrm{ml})$ than those obtained in this work $(5 \mu \mathrm{g} / \mathrm{ml})$ but using more complicated conditions (employing solid-phase extraction, internal standard, and UV detection at $200 \mathrm{~nm}$ ) whereas another study using microchip electrophoresis with conductivity detection [12] gave lower LOQ for methylparaben $(0.7 \mu \mathrm{g} / \mathrm{ml})$ but higher LOQ for propylparaben $(6.0 \mu \mathrm{g} / \mathrm{ml})$ comparing to this work. Better sensitivity for chloramphenicol was also achieved with electrochemical detection (LOD about $0.3 \mu \mathrm{g} / \mathrm{ml}$ ) [8]. However, there was no available method for simultaneous assay of chloramphenicol, methylparaben, and propylparaben in eye-drops before this study, and this work was successful in providing a simple, easy-to-use method with sufficient reliability and sensitivity and without the need of elaborate sample preparation and being feasible on a commercial instrument for routine quality control. The suitability of this method was also proved by the results obtained on real eye-drops samples (Table 2). These results showed that these 
TABLe 2: Assay results of eye-drops sample.

\begin{tabular}{lccc}
\hline Analytes & Chloramphenicol & Propylparaben & Methylparaben \\
\hline Labeled amount & $0.4 \%(32 \mathrm{mg} / 8 \mathrm{ml})$ & $0.002 \%(0.16 \mathrm{mg} / 8 \mathrm{ml})$ & $0.018 \%(1.44 \mathrm{mg} / 8 \mathrm{ml})$ \\
Average content $(\%$, comparing to labeled amount, $n=6)$ & 98.1 & 104.6 & 1.6 \\
RSD of content $(\%)$ & 1.0 & 1.2 & 1.3 \\
\hline
\end{tabular}

eye-drops meet common requirements of the content of active ingredient (95-105\% of the labeled amount) and preservative (80-120\% of the labeled amount) for pharmaceutical products.

\section{Conclusion}

In this study, a green, cost-effective, and simple CZE method has been developed for simultaneous assay of chloramphenicol, propylparaben, and methylparaben in eye-drops. The method was validated according to current requirements, and its reliability, through the studies of specificity, linearity, precision, accuracy, and robustness, was proved as acceptable for the intended application. Results of this study also confirmed the possibility and the need of promoting "green chemistry" in drug quality control activities, through the employment of analytical techniques friendly with the environment like capillary electrophoresis.

\section{Data Availability}

The data used to support the findings of this study are available from the corresponding author (ledinhchi@ gmail.com) upon request.

\section{Conflicts of Interest}

The authors declare no conflicts of interest regarding the publication of this study.

\section{References}

[1] A. T. Akopian and A. F. Pukhner, "The action of synthomycin, chloramphenicol and aureomycin on secondary infections accompanying Trachoma," Journal of Microbiology, Epidemiology and Immunobiology, vol. 28, no. 3, pp. 420-423, 1957.

[2] J. B. Alavi, "Aplastic anemia associated with intravenous chloramphenicol," American Journal of Hematology, pp. 375-379, 1983.

[3] S. I. Crovetto, E. Moreno, A. L. Dib, M. Espigares, and E. Espigares, "Bacterial toxicity testing and antibacterial activity of parabens," Toxicological and Environmental Chemistry, vol. 99, pp. 858-868, 2017.

[4] Cosmetic Ingredient Review Expert Panel, "Final amended report on the safety assessment of methylparaben, ethylparaben, propylparaben, isopropylparaben, butylparaben, isobutylparaben, and benzylparaben as used in cosmetic products," International Journal of Toxicology, vol. 27, no. Suppl.4, pp. 1-82, 2008.

[5] British Pharmacopoeia Commission, British Pharmacopoeia 2020, British Pharmacopoeia Commission, London, UK, Monograph: Chloramphenicol (electronic version), 9th. edition, 2020.

[6] I. Ali, H. Y. Aboul-Enein, V. K. Gupta, P. Singh, and U. Negi, "Analyses of chloramphenicol in biological samples by
HPLC," Analytical Letters, vol. 42, no. 10, pp. 1368-1381, 2009.

[7] W. Jin, X. Ye, D. Yu, and Q. Dong, "Measurement of chloramphenicol by capillary zone electrophoresis following end-column amperometric detection at a carbon fiber microdisk array electrode," Journal of Chromatography B: Biomedical Sciences and Applications, vol. 741, no. 2, pp. 155-162, 2000.

[8] A. Wang, L. Zhang, and Y. Fang, "Determination and separation of chloramphenicol and its hydrolysate in eye-drops by capillary zone electrophoresis with amperometric detection," Analytica Chimica Acta, vol. 394, no. 2-3, pp. 309-316, 1999.

[9] P. Talebizadehsardari, Z. Aramesh-Boroujeni, M. M. Foroughi et al., "Synthesis of carnation-like $\mathrm{Ho} 3+/ \mathrm{Co} 3 \mathrm{O} 4$ nanoflowers as a modifier for electrochemical determination of chloramphenicol in eye dropflowers as a modifer for electrochemical determination of chloramphenicol in eye drop," Microchemical Journal, vol. 159, Article ID 105535, 2020.

[10] A. Zgoła-Grzeskowiak, J. Werner, M. Jeszka-Skowrona, and B. Czarczynska-Goslinska, "Determination of parabens in cosmetic products using high performance liquid chromatography with fluorescence detection," Analytical Methods, vol. 8, 2016.

[11] U. D. Uysal and T. Güray, "Determination of parabens in pharmaceutical and cosmetic products by capillary electrophoresis," Journal of Analytical Chemistry, vol. 63, no. 10, pp. 982-986, 2007.

[12] P. Troška, E. Pobozy, Z. Némethová, and M. Masár, "Determination of commonly used excipients in pharmaceutical preparations by microchip electrophoresis with conductivity detection," Chromatographia, vol. 82, pp. 741-748, 2019.

[13] M. Collado, V. E. Mantovani, H. C. Goicoechea, and A. C. Olivieri, "Simultaneous spectrophotometric-multivariate calibration determination of several components of ophthalmic solutions: phenylephrine, chloramphenicol, antipyrine, methylparaben and thimerosal," Talanta, vol. 52, no. 5, pp. 909-920, 2000.

[14] The International Council for Harmonisation of Technical Requirements for Pharmaceuticals for Human Use, Validation of Analytical Procedures: Text and Methodology Q2(R1), The International Council for Harmonisation of Technical Requirements for Pharmaceuticals for Human Use, Geneva, Switzerland, 2005.

[15] AOAC International, "Appendix F: guidelines for standard method performance requirements," in AOAC Official Method of Analysis, AOAC International, Washington, DC, USA, 2016.

[16] H. Naseef, R. Moqadi, and M. Qurt, "Development and validation of an HPLC method for determination of antidiabetic drug alogliptin benzoate in bulk and tablets," Journal of Analytical Methods in Chemistry, vol. 2018, Article ID 1902510, 7 pages, 2018.

[17] D. A. Armbruster, M. D. Tillman, and L. M. Hubbs, "Limit of detection (LQD)/limit of quantitation (LOQ): comparison of the empirical and the statistical methods exemplified with 
GC-MS assays of abused drugs," Clinical Chemistry, vol. 40, no. 7, pp. 1233-1238, 1994.

[18] A. G. González and M. A. Herrador, "A practical guide to analytical method validation, including measurement uncertainty and accuracy profiles," Trends in Analytical Chemistry, vol. 26, no. 3, pp. 227-238, 2007.

[19] C. M. Riley, T. W. Rosanske, and S. R. R. Riley, Specification ofDrug Substances and Products: Development and Validation of Analytical Methods, Elsevier, New York, NY, USA, 2014.

[20] M. E. Swartz and I. Krull, "Method validation and robustness," LCGC North America, vol. 24, no. 5, pp. 480-490, 2006.

[21] B. L. Woods and R. A. Walker, "pH effects on molecular adsorption and solvation of p-nitrophenol at silica/aqueous interfaces," The Journal of Physical Chemistry A, vol. 117, no. 29, pp. 6224-6233, 2013.

[22] T. Angelov, A. Vlasenko, and W. Tashkov, "HPLC determination of $\mathrm{pKa}$ of parabens and investigation on their lipophilicity parameters," Journal of Liquid Chromatography and Related Technologiesw, vol. 31, pp. 188-197, 2008.

[23] E. T. Wise and S. G. Weber, "A simple partitioning model for reversibly crosslinked polymers and application to the poly(vinyl alcohol)/borate system ("Slime")," Macromolecules, vol. 28, no. 24, pp. 8321-8327, 1995.

[24] Z. Qiang and C. Adams, "Potentiometric determination of acid dissociation constants ( $\mathrm{pKa}$ ) for human and veterinary antibiotics," Water Research, vol. 38, no. 12, pp. 2874-2890, 2004.

[25] K. C. James and R. H. Leach, "A borax-chloramphenicol complex in aqueous solution," Journal of Pharmacy and Pharmacology, vol. 22, no. 8, pp. 612-614, 1970. 